\title{
Library Use of Web-based Research Guides
}

Jimmy Ghaphery and Erin White

\section{ABSTRACT}

This paper describes the ways in which libraries are currently implementing and managing webbased research guides (a.k.a. Pathfinders, LibGuides, Subject Guides, etc.) by examining two sets of data from the spring of 2011. One set of data was compiled by visiting the websites of ninety-nine American university ARL libraries and recording the characteristics of each site's research guides. The other set of data is based on an online survey of librarians about the ways in which their libraries implement and maintain research guides. In conclusion, a discussion follows that includes implications for the library technology community.

\section{SELECTED LITERATURE REVIEW}

While there has been significant research on library research guides, there has not been a recent survey either of the overall landscape or of librarian attitudes and practices. There has been recent work on the efficacy of research guides as well as strategies for their promotion. There is still work to be done on developing a strong return on investment metric for research guides, although the same could probably be said for other library technologies including websites, digital collections, and institutional repositories.

Subject-based research guides have a long history in libraries that predates the web as a servicedelivery mechanism. A literature-review article from 2007 found that research on the subject gained momentum around 1996 with the advent of electronic research guides, and that there was a need for more user-centric testing. ${ }^{1}$ By the mid-2000s, it was rare to find a library that did not offer research guides through its website. ${ }^{2}$ The format of guides has certainly shifted over time to database-driven efforts through local library programming and commercial offerings.

A number of other articles start to answer some of the questions about usability posed in the 2007 literature review by Vileno. In 2008, Grays, Del Bosque, and Costello used virtual focus groups as a test bed for guide evaluation. ${ }^{3}$ Two articles from the August 2010 issue of the Journal of Library Administration contain excellent literature reviews and look toward marketing, assessment, and best practices. ${ }^{4}$ Also in 2010, Vileno followed up on the 2007 literature review with usability testing that pointed toward a number of areas in which users experienced difficulties with research guides. ${ }^{5}$

Jimmy Ghaphery (jghapher@vcu.edu) is Head, Library Information Systems and Erin White (erwhite@vcu.edu) is Web Systems Librarian, Virginia Commonwealth University Libraries, Richmond, VA. 
In terms of cross-library studies, an interesting collaboration in 2008 between Cornell and Princeton Universities found that students, faculty, and librarians perceived value in research guides, but that their qualitative comments and content analysis of the guides themselves indicated a need for more compelling and effective features. ${ }^{6}$ The work of Morris and Grimes from 1999 should also be mentioned; the authors surveyed 53 university libraries, finding that it was rare to find a library with formal management policies for their research guides. ${ }^{7}$

Most recently, LibGuides has emerged as a leader in this arena, offering a popular software-as-aservice (SAAS) model and as such is not yet heavily represented in the literature. A multichapter LibGuides LITA guide is pending publication and will cover such topics as implementing and managing LibGuides, setting standards for training and design, and creating and managing guides.

\section{ARL GUIDES LANDSCAPE}

During the week of March 3rd, 2011, the authors visited the websites of 99 American university ARL libraries to determine the prevalence and general characteristics of their subject-based research guides. In general, the visits reinforced the overarching theme within the literature that subject-based research guides are a core component of academic library web services. All 99 libraries offered research guides that were easy to find from the library home page. LibGuides was very prominent as a platform, in production at 67 of the 99 libraries. Among these, it appeared that at least 5 libraries were in the process of migrating from a previous system (either a homegrown, database-driven site or static HTML pages) to LibGuides.

In addition to the presence and platform, the authors recorded additional information about the scope and breadth of each site's research guides. For each site, the presence of course-based research guides was recorded. In some cases the course guides had a separate listing, whereas in others they were intermingled with the subject-based research guides. Course guides were found on 75 of the 99 libraries visited. Of these, 63 were also LibGuides sites. It is certainly possible that course guides are being deployed at some of the other libraries but were not immediately visible in visiting the websites, or that course guides may be deployed through a course management system. Nonetheless, it appears that the use of LibGuides encourages the presence of public-facing course guides. Qualitatively, there was wide diversity of how course guides were organized and presented, varying from a simple A-to-Z listing of all guides to separately curated landing pages specifically organized by discipline.

The number of guides was recorded for each LibGuides site. It was possible to append "/browse.php?o=a" to the base URL to determine how many guides and authors were published at each site. This PHP extension was the publicly available listing of all guides on each LibGuides platform. The "/browse.php?o=a" extension no longer publicly reports these statistics; however, findings could be reproduced by manually counting the number of guides and authors on each site. The authors confirmed the validity of this method in the fall of 2011 by revisiting four sites and finding that the numbers derived from manual counting were in line with the previous findings. Of 
the 63 LibGuides sites we observed, a total of 14,522 guides were counted from 2,101 authors for an average of 7 guides per author. On average, each site had 220 guides from 32 authors (median of 179 guides; 29 authors). At the high end of the scale, one site had 713 guides from 46 authors. Based on the volume observed, libraries appear to be investing significant time toward the creation, and presumably the maintenance, of this content. In addition to creation and ongoing maintenance, such long lists of topics raise a number of usability issues that libraries will also be wise to keep in mind. 8

\section{SURVEY}

The literature review and website visits call out two strong trends:

1. Research guides are as commonplace as books in libraries,

2. LibGuides is the elephant in the room, so much so that it is hard to discuss research guides without discussing LibGuides.

Based on preliminary findings from the literature review and survey, we looked to further describe how libraries are supporting, innovating, implementing, and evaluating their research guides. A ten-question survey was designed to better understand how research guides sit within the cultural environment of libraries. It was distributed to a number of professional discussion lists the week of April 19, 2011 (see appendix). The following lists were used in an attempt to get a balance of opinion from populations of both technical and public services librarians: code4lib, web4lib, lita-l, lib-ref-l, and ili-l. The survey was made available for two weeks following the list announcements.

Survey response was very strong, with 198 responses (188 libraries) received without the benefit of any follow-up recruitment. Ten institutions submitted more than one response. In these cases only the first response was included for analysis. We did not complete a response for our own institution.

The vast majority $(155,82 \%)$ of respondents were from college or university libraries. Of the remaining 33, 24 (13\%) were from community college libraries, with only 9 (5\%) identifying themselves as public, school, private, or governmental. Among the college and university libraries, 17 (9\%) identified themselves as members of the ARL, which comprises 126 members. ${ }^{9}$ In terms of "what system best describes your research guides by subject?" the results were similar to the survey of ARL websites. Most libraries $(129,69 \%)$ reported LibGuides as their system, followed by "customized open source system" and "static HTML pages," both at 20 responses (11\% each). Sixteen libraries (9\%) reported using a homegrown system, with three libraries (2\%) reporting "other commercial system."

In terms of initiating and maintaining a guides system, much of the work within libraries seems to be happening outside of library systems departments. When asked which statement best described who selected the guides system, 67 respondents (36\%) indicated their library research 
guides were "initiated by Public Services," followed closely by "more of a library-wide initiative" at 63 responses (34\%). In the middle at 34 responses (18\%) was "initiated by an informal crossdepartmental group." Only 10 respondents (5\%) selected "initiated by Systems," with the top down approach of "initiated by Administration" gathering 14 responses (7\%). When narrowing the responses to those sites that are using LibGuides or Campus Guides, the portrait is not terribly different, with 36\% library-wide, 35\% Public Services, 18\% informal cross-departmental, 7\% Administration, and Systems trailing at $4 \%$.

Likewise there was not a strong indication of library systems involvement in maintaining or supporting research guides. Sixty-nine responses (37\%) indicated "no ongoing involvement" and an additional 35 (19\%) indicated "N/A we do not have a Systems Department." There were only 21 responses (11\%) stating "considerable ongoing involvement," with the balance of 63 responses (34\%) for "some ongoing involvement." Not surprisingly, there was a correlation between the type of research guide and the amount of systems involvement. For sites running a "customized open source system," "other commercial system," or "homegrown system," at least $80 \%$ of responses indicated either "considerable" or "some" ongoing systems involvement. In contrast, $37 \%$ of sites running LibGuides or CampusGuides indicated "considerable" or "some" technical involvement. Further, the LibGuides and CampusGuides users recorded the highest percentage (43\%) of "no ongoing involvement" compared to $37 \%$ of all respondents. Interestingly, $20 \%$ of LibGuides and Campus Guides users answered "N/A we do not have a Systems Department," which is not significantly higher than all respondents for this question at $19 \%$.

The level of interaction between research guides and enterprise library systems was not reported as strong. When asked "which statement best describes the relationship between your web content management system and your research guides?" 112 responses (60\%) indicated that "our content management system is independent of our research guides" with an additional 51 responses (27\%) indicating that they did not have a content management system (CMS). Only 12 respondents (6\%) said that their CMS was integrated with their research guides with a remaining 13 (7\%) saying that their CMS was used for "both our website and our research guides." A similar portrait was found in seeking out the relationship between research guides and discovery/federated search tools. When asked "which statement best describes the relationship between your discovery/federated search tool and your research guides?" roughly half of the respondents $(96,51 \%)$ did not have a discovery system ("N/A we do not have a discovery tool"). Only 12 respondents (6\%) selected "we prominently feature our discovery tool on our guides," whereas more than double that number, 26 (14\%), said "we typically do not include our discovery tool on our guides." Fifty four respondents (29\%) took the middle path of "our discovery tool is one of many search options we feature on our guides." In the case of both discovery systems and content management systems, it seems that research guides are typically not deeply integrated. When asked "what other type of content do you host on your research guides system?" respondents selected from a list of choices as reflected in table 1. 


\begin{tabular}{|l|l|l|l|}
\hline Answer & Total & Percent & LibGuides/CampusGuides \\
\hline Course pages & 127 & $68 \%$ & $74 \%$ \\
\hline "How to" instruction & 123 & $65 \%$ & $77 \%$ \\
\hline $\begin{array}{l}\text { Alphabetical list of all } \\
\text { databases }\end{array}$ & 76 & $40 \%$ & $42 \%$ \\
\hline $\begin{array}{l}\text { "About the library" information } \\
\text { for example hours, directions, } \\
\text { staff directory, event) }\end{array}$ & 59 & $31 \%$ & $35 \%$ \\
\hline $\begin{array}{l}\text { Digital collections } \\
\text { Everything-we use the } \\
\text { research guide platform as our } \\
\text { website }\end{array}$ & 16 & $9 \%$ & $9 \%$ \\
\hline \begin{tabular}{l} 
None of the above \\
\hline
\end{tabular} & 17 & $9 \%$ & $2 \%$ \\
\hline
\end{tabular}

Table 1. Other Types of Content Hosted on Research Guides System

These answers reinforce the portrait of integration within the larger library web presence. While the research guides platform is an important part of that presence, significant content is also being managed by libraries through other systems. It is also consistent with the findings from the ARL website visits, where course pages were consistently found within the research guides platform. For sites reporting LibGuides or CampusGuides as their platform, inclusion of course pages and how-to instruction was even higher, at $74 \%$ and $77 \%$, respectively.

Another multi-answer question sought to determine what types of policies are being used by libraries for the management of research guides: "which of the following procedures or policies do you have in place for your research guides?" Responses are summarized in table 2. 


\begin{tabular}{|l|l|l|l|}
\hline Answer & Total & Percent & $\begin{array}{l}\text { Percent using } \\
\text { LibGuides/CampusGuides }\end{array}$ \\
\hline $\begin{array}{l}\text { Style guides for consistent } \\
\text { presentation }\end{array}$ & 105 & 56 & 58 \\
\hline $\begin{array}{l}\text { Maintenance and upkeep of } \\
\text { guides }\end{array}$ & 94 & 50 & 53 \\
\hline Link checking & 87 & 46 & 50 \\
\hline $\begin{array}{l}\text { Required elements such as } \\
\text { contact information, chat, } \\
\text { pictures, etc. }\end{array}$ & 78 & 41 & 56 \\
\hline $\begin{array}{l}\text { Training for guide creators } \\
\text { Transfer of guides to } \\
\text { another author due to } \\
\text { separation or change in } \\
\text { duties }\end{array}$ & 73 & 39 & 43 \\
\hline $\begin{array}{l}\text { Defined scope of } \\
\text { appropriate content }\end{array}$ & 43 & 23 & 41 \\
\hline $\begin{array}{l}\text { Allowing and/or moderating } \\
\text { user tags, comments, ratings }\end{array}$ & 36 & 19 & 22 \\
\hline $\begin{array}{l}\text { None of the above } \\
\text { vocabulary/tagging system } \\
\text { for managing guides }\end{array}$ & 36 & 19 & 19 \\
\hline
\end{tabular}

Table 2. Management Policies/Procedures for Research Guides

While nearly one in five libraries reported none of the policies in place at all, the responses indicate that there is effort being applied toward the management of these systems. The highest percentage for any given policy was $56 \%$ for "style guides for consistent presentation." Best practices in these areas could be emerging or many of these policies could be specific to individual library needs. As with the survey question on content, the research-guides platform also has a role with the LibGuides and CampusGuides users reporting much higher rates of policies for "controlled vocabulary/tagging" ( $25 \%$ vs. $12 \%$ ) and "required elements" (56\% vs. $41 \%$ ). In both 
of these cases, it is likely that the need for policies arise from the availability of these features and options that may not be present in other systems. Based on this supposition, it is somewhat surprising that the LibGuides and CampusGuides sites reported the same lack of policy adoption (none of the above; 19\%).

The final question in the survey further explored the management posture for research guides by asking a free-text question: "how do you evaluate the success or failure of your research guides?" Results were compiled into a spreadsheet. The authors used inductive coding to find themes and perform a basic data analysis on the responses, including a tally of which evaluation methods were used and how often. One in five institutions (37 respondents, 19.6\%) looked only to usage stats, while seven respondents (4\%) indicated that their library had performed usability testing as part of the evaluation. Forty-our respondents (23.4\%) said they had no evaluation method in place ("Ouch! It hurts to write that."), though many expressed an interest or plans to begin evaluation.

Another emerging theme included ten respondents who quantified success in terms of library adoption and ease of use. This included one respondent who had adopted LibGuides in light of prohibitive IT regulations ("We choose LibGuides because IT would not allow us to create class specific research webpages"). Several institutions also expressed frustration with the survey instrument because they were in the process of moving from one guides system to another and were not sure how to address many questions. Most responses indicated that there are more questions than answers regarding the efficacy of their research guides, though the general sentiment toward the idea of guides was positive, with words such as "positive," "easy," "like," and "love" appearing in 16 responses. Countering that, 5 respondents indicated that their libraries' research-guides projects had fallen through.

\section{CONCLUSION}

This study confirms previous research that web-based research guides are a common offering, especially in academic libraries. Adding to this, we have recorded a quantitative adoption of LibGuides both through visiting ARL websites and through a survey distributed to library listservs. Further, this study did not find a consistent management or assessment practice for library research guides. Perhaps the most interesting finding from this study is the role of library systems departments with regard to research guides. It appears that many library systems departments are not actively involved in either the initiation or ongoing support of web-based research guides.

What are the implications for the library technology community and what questions arise for future research? The apparent ascendancy of LibGuides over local solutions is certainly worth considering and in part demonstrates some comfort within libraries for cloud computing and SAAS. Time will tell how this might spread to other library systems. The popularity of LibGuides, at its heart a specialized content management system, also calls into question the vitality and adaptability of local content management system implementations in libraries. More generally, does the desire to professionally select and steward information for users on research guides indicate librarian misgivings about the usability of enterprise library systems? How do attitudes 
toward research guides differ between public services and technical services? Hopefully these questions serve as a call for continued technical engagement with library research guides. What shape that engagement may have in the future is an open question, but based on the prevalence and descriptions of current implementations, such consideration by the library technology community is worthwhile.

\section{REFERENCES}

1. Luigina Vileno, "From Paper to Electronic, the Evolution of Pathfinders: A Review of the Literature," Reference Services Review 35, no. 3 (2007): 434-51.

2. Martin Courtois, Martha Higgins, Aditya Kapur, "Was this Guide Helpful? Users' Perceptions of Subject Guides," Reference Services Review 33 , no. 2 (2005): 188-96.

3. Lateka J. Grays, Darcy Del Bosque, and Kristen Costello, "Building a Better M.I.C.E. Trap: Using Virtual Focus Groups to Assess Subject Guides for Distance Education Students," Journal of Library Administration 48, no. 3/4 (2008): 431-53.

4. Mira Foster et al., "Marketing Research Guides: An Online Experiment with LibGuides," Journal of Library Administration 50, no. 5/6 (July/September, 2010): 602-16; Alisa C. Gonzalez and Theresa Westbrock, "Reaching Out with LibGuides: Establishing a Working Set of Best Practices," Journal of Library Administration 50, no. 5/6 (July/September, 2010): 638-56.

5. Luigina Vileno, "Testing the Usability of Two Online Research Guides," Partnership: The Canadian Journal of Library and Information Practice and Research 5, no. 2 (2010), http://journal.lib.uoguelph.ca/index.php/perj/article/view/1235 (accessed August 8, 2011).

6. Angela Horne and Steve Adams, "Do the Outcomes Justify the Buzz? An Assessment of LibGuides at Cornell University and Princeton University-Presentation Transcript," presented at the Association of Academic and Research Libraries, Seattle, WA, 2009, http://www.slideshare.net/smadams/do-the-outcomes-justify-the-buzz-an-assessment-ofLibGuides-at-cornell-university-and-princeton-university (accessed August 8, 2011).

7. Sarah Morris and Marybeth Grimes, "A Great Deal of Time and Effort: An Overview of Creating and Maintaining Internet-based Subject Guides," Library Computing 18, no. 3 (1999): 213-16.

8. Mathew Miles and Scott Bergstrom, "Classification of Library Resources by Subject on the Library Website: Is There an Optimal Number of Subject Labels?" Information Technology \& Libraries 28, no. 1 (March 2009): 16-20, http://www.ala.org/lita/ital/files/28/1/miles.pdf (accessed August 8, 2011).

9. Association of Research Libraries, "Association of Research Libraries: Member Libraries," http://www.arl.org/arl/membership/members.shtml (accessed October 24, 2011). 


\section{Appendix. Survey}

\section{Library Use of Web-based Research Guides}

Please complete the survey below.

We are researching libraries' use of web-based research guides. Please consider filling out the following survey, or forwarding this survey to the person in your library who would be in the best position to describe your library's research guides.

Responses are anonymous.

Thank you for your help!

Jimmy Ghaphery, VCU Libraries

Erin White, VCU Libraries

1) What is the name of your organization?

Note that the name of your organization will only be used to make sure multiple responses from the same organization are not received. Any publication of results will not include specific names of organizations.

2) Which choice best describes your library?

O ARL

o University library

o College library

o Community college library

o Public library

o School library

o Private library

o Governmental library

o Nonprofit library

3) What type of system best describes your research guides by subject?

o LibGuides or CampusGuides

o Customized open source system

o Other commercial system

o Homegrown system

o Static HTML pages

4) Which statement best describes the selection of your current research guides system?

o Initiated by Administration

o Initiated by Systems

o Initiated by Public Services

o Initiated by an informal cross-departmental group

o More of a library-wide initiative 
5) How much ongoing involvement does your Systems Department have with the management of your research guides?

o No ongoing involvement

o Some ongoing involvement

o Considerable ongoing involvement

o N/A we do not have a Systems Department

6) What other type of content do you host on your research guides system?

o Course pages

o "How to" instruction

o Alphabetical list of all databases

o "About the library" information (for example: hours, directions, staff directory, events)

o Digital collections

o Everything-we use the research guide platform as our website

o None of the above

7) Which statement best describes the relationship between your discovery/federated search tool and your research guides?

o We typically do not include our discovery tool on our guides

o Our discovery tool is one of many search options we promote on our guides

o We prominently feature our discovery tool on our guides

o N/A We do not have a discovery tool

8) Which statement best describes the relationship between your Web Content Management System and your research guides?

o Our content management system is independent of our research guides

o Our content management system is integrated with our research guides

o Our content management system is used for both our website and our research guides

o N/A we do not have a content management system

9) Which of the following procedures or policies do you have in place for your research guides?

o Defined scope of appropriate content

o Required elements such as contact information, chat, pictures, etc.

o Style guides for consistent presentation

o Allowing and/or moderating user tags, comments, ratings

o Training for guide creators

o Controlled vocabulary/tagging system for managing guides

0 Maintenance and upkeep of guides

o Link checking 
o Transfer of guides to another author due to separation or change in duties

o None of the above

10) How do you evaluate the success or failure of your research guides?

[Free Text] 